\title{
DEFENSA Y ADMINISTRACIÓN MILITAR DEL REINO DE GRANADA EN ÉPOCA DE FELIPE III: PERMANENCIAS Y CAMBIOS EN UNA FRONTERA MEDITERRÁNEA
}

\author{
Antonio Jiménez Estrella \\ Universidad de Granada
}

\begin{abstract}
RESUMEN. El objetivo de este artículo es analizar el modo en que se articuló la defensa de la frontera marítima del reino de Granada en época de Felipe III, una etapa de profundas transformaciones sociales y económicas, tras la expulsión de los moriscos del territorio. Para ello, se presta especial atención a los cambios y permanencias que hubo en la administración militar y los problemas estructurales de coordinación, financiación y funcionamiento del sistema defensivo. Asimismo, el estudio se sitúa en el contexto de la estructura defensiva peninsular y de la activa política mediterránea y norteafricana llevada a cabo por Monarquía Hispánica en este período, así como las consecuencias que ésta y el incremento de los ataques corsarios en toda el área mediterránea tuvieron sobre las costas del reino.
\end{abstract}

Palabras clave: Reino de Granada, siglo XVII, defensa de la costa, corsarios, norte de África, Mediterráneo, administración militar.

ABSTRACT. The objective of this article is to study the working of defense of the maritime border of the Kingdom of Granada during the reign of Philip III, a period of profound social and economic transformations, after the expulsion of the moorishs from the territory. For this, we pay special attention to the changes and permanence that occurred in the military administration and the structural problems of coordination, financing and operation of the defensive system. Likewise, we contextualize the study in the context of the peninsular defensive structure, the active Mediterranean and North African policy maintained by the hispanic monarchy in this period, as well as the consequences that such policy, and the increase of the corsairs attacks throughout the Mediterranean area they had on the coast of the kingdom.

Keywords: Kingdom of Granada, $17^{\text {th }}$ Century, coast defense, corsairs, North of Africa, Mediterranean sea, military administration.

Recibido: 21-10-2020 . Aceptado: 2-05-2021 . jimeneze@ugr.es 
Desde su incorporación a CAStilla, el reino de Granada se convirtió en una frontera marítima de gran importancia para la monarquía, estableciéndose, a partir de entonces, un sistema defensivo territorial y marítimo que contaba con un importante contingente de efectivos profesionales y a sueldo. El mismo estaba articulado en tres niveles de protección. El primero era una red de alerta litoral, compuesta por las torres, atalayas y guardas de costa, cuya función era dar avisos cuando se producía el avistamiento de naves enemigas o cualquier intento de incursión sobre las más de ochenta leguas de costa que componía el litoral granadino. Este abarcaba desde Gibraltar, pasando por los enclaves de Estepona, Marbella, Málaga, Almuñécar, Salobreña, Motril, Adra, Almería y el cabo de Gata, hasta las últimas estribaciones orientales del reino, en Mojácar y Vera, hasta llegar a San Juan de los Terreros, en la frontera con el reino de Murcia (Gámir Sandoval, 1943; Szmolka, 1979; Vera Delgado, 1986; López de Coca, 1993). El segundo estaba integrado por un importante conjunto de fortalezas, destacadas en las cabezas de distrito costeras más importantes y en los enclaves y nudos de comunicación de mayor relevancia estratégica, bajo el control de una serie de alcaides y tenientes que debían velar por su conservación, mantenimiento y el pago de los sueldos de las guarniciones que en ellas habitaban, y que en su mayoría patrimonializaron para convertirlas en fuentes de pensiones y honores (López de Coca, 1989 y Jiménez Estrella, 2007). Tanto la red de atalayas como las fortalezas eran, en su mayor parte, construcciones de época nazarí, que fueron reutilizadas posteriormente por la nueva administración castellana. A ellas se unieron otras edificaciones poliorcéticas posteriores bajo administración de los Habsburgo, sometidas a un régimen de inspecciones y visitas que no siempre cosechó los resultados esperados (Ruiz Povedano, 1979 y Jiménez Estrella, 2017). El tercer nivel, por último, estaba compuesto por tropas ordinarias y de guardias viejas de Catilla, distribuidas en distintas compañías de infantería y caballería costera, apostadas en los principales núcleos y cabezas de distrito de la costa, cuya función era esencial en las labores de rastreo y la hora de repeler posibles incursiones y ataques de embarcaciones enemigas, en su mayoría de bandera islámica (Jiménez Estrella, 2006). Aparte de este importante contingente profesional, situado en torno a unas 1.600 plazas efectivas - sobre una planta teórica de unos 1.900 hombres - , las labores de defensa eran reforzadas, en caso de rebato costero y llamamientos en armas, por parte de las compañías de tropas concejiles de aquellas ciudades, villas y lugares que se encontraban en la costa o en las doce leguas de distancia de esta al interior. Se trataba de una población civil que, sobre el papel, debía estar adiestrada y armada, preparada para asistir y auxiliar militarmente a los soldados de las compañías y de las guarniciones, pero que en la práctica presentaba importantes problemas para su adiestramiento y movilización (Contreras Gay, 1997). 
Todo este entramado defensivo estaba bajo mando del capitán general del reino, institución que estuvo en poder de los Mendoza en el siglo Xvi, hasta la pérdida del mismo tras la rebelión morisca ${ }^{1}$. Durante el período morisco, este modelo de defensa y administración militar se mantuvo y funcionó como un sistema con cierta coherencia en su estructura y con una clara ventaja sobre otros dispositivos defensivos peninsulares. Gracias, en gran medida, al mantenimiento de una fiscalidad diferencial sobre las espaldas de la población morisca, el sistema se autofinanciaba. Por ello no dependía del envío regular de remesas desde Madrid ni de largos procesos de negociación fiscal con las autoridades y representantes locales, como ocurría, por ejemplo, en Navarra, Guipúzcoa o Valencia (Escribano Páez, 2015; Truchuelo García, 2004; Pardo Molero, 2001). No obstante, el conflicto, la expulsión de los naturales y la pérdida del cargo de capitanes generales por parte de los Mendoza tuvieron consecuencias muy importantes sobre el dispositivo militar. Entre los cambios más relevantes, destacan aquellos que afectaron al sistema defensivo de la costa y a su modelo de financiación, pues durante mucho tiempo los moriscos habían sido los sujetos fiscales en los que se había cargado el sostenimiento de la defensa, por medio de los servicios ordinarios y extraordinarios, así como la denominada farda de la mar, que había servido para sostener el cinturón de torres vigía y centinelas (Vincent, 1985; Castillo Fernández, 1992). La expulsión dejó un importante vacío demográfico que trastocó por completo el modelo fiscal en el que se sostenía el sistema. Desaparecidos los naturales, se recurrió a lo procedido de las ventas y censos de los bienes que se les confiscaron tras su deportación, consignando una parte de la llamada Renta de Población a este efecto: unos 60.000 ducados que, dadas las acuciantes necesidades de la tropa profesional, se elevaron a 80.000 en 1591 (Jiménez Estrella, 2004, p. 240). Además, la guerra dejó sin población zonas especialmente sensibles a nivel de defensa, sobre todo en el área de las Alpujarras y el sector que iba desde la ciudad de Almería hasta Vera y Mojácar. Por ello, en años posteriores se llevaron a cabo importantes políticas de repoblación, en las que el elemento militar debía ser primordial, del mismo modo que la militarización y armamento de los civiles se iba a convertir en un requisito fundamental para la concesión de suertes y franquezas durante la repoblación, a fin de incentivar la defensa (Sánchez Ramos, 1995).

El objetivo de este trabajo es mostrar cómo se articuló dicho sistema defensivo, los cambios y las permanencias que hubo en la administración militar granadina y los problemas estructurales de coordinación, financiación y funcionamiento durante el reinado de Felipe III. Se trata de un período que no ha sido objeto de una investigación profunda, salvo algunos trabajos de carácter general sobre la frontera marítima y la organización de la defensa del reino de Granada en el XVII (Contreras Gay, 2000).

1 Un estudio pormenorizado de la gestión de los Mendoza al frente del cargo y de la defensa del territorio, en Jiménez Estrella (2004). 
Ello permitirá arrojar nuevas luces sobre una etapa que fue especialmente activa en lo concerniente a la política mediterránea y norteafricana de la Monarquía Hispánica y el modo en que esta política tuvo consecuencias sobre el día a día en las costas del reino granadino, a raíz del notable incremento de los ataques piráticos y corsarios en toda el área mediterránea durante este período.

\section{La estructura militar, la Capitanía General y sus competencias}

A fines de 1601, tal y como se detalla en la tabla 1, el sistema defensivo de la costa del reino de Granada, sobre una dotación teórica de 1.930 hombres, no llegaría a las 1.300 plazas. La estructura y organigrama reflejados en la tabla 1 se mantuvieron durante todo el período aquí analizado, con algunas oscilaciones en el déficit entre la planta teórica y la dotación efectiva, en función de determinadas coyunturas, vinculadas con los problemas que, desde finales del siglo XVI, afectaban a la consignación de 80.000 ducados que se cargaban en la Renta de Población, y otros factores relacionados con la comisión de determinados fraudes, corruptelas y errores en la elaboración de las muestras con las que se confeccionaban las nóminas.

Tabla 1. Dispositivo militar permanente de la costa del reino de Granada (1601)

\begin{tabular}{|l|c|}
\hline \multicolumn{2}{|c|}{ Guardas, escuchas, atajadores y oficiales de las guardas de costa ${ }^{2}$} \\
\hline Localización & Plazas \\
\hline Partido de Vera y Mojácar (Obispado de Almería) & 31 \\
\hline Partido de Almería (Obispado de Almería) & 55 \\
\hline Partido de Adra (Arzobispado de Granada) & 26 \\
\hline Partido de Motril (Arzobispado de Granada) & 33 \\
\hline Partido de Almuñécar (Arzobispado de Granada) & 17 \\
\hline Partido de Vélez Málaga (Obispado de Málaga) & 39 \\
\hline Partido de Málaga (Obispado de Málaga) & 36 \\
\hline Partido de Marbella (Obispado de Málaga) & 35 \\
\hline Dotación real & 272 \\
\hline Dotación teórica & 296 \\
\hline Déficit & 20 \\
\hline
\end{tabular}

2 Aparte de las 264 guardas, escuchas y velas que debía haber en las torres, se cuentan 8 requeridores, 7 visitadores y 16 atajadores de acaballo, más un contador de la razón, AGS, Guerra Antigua, leg. 600, f. 154. 


\begin{tabular}{|c|c|c|}
\hline \multicolumn{3}{|c|}{ Compañías de infantería ordinaria } \\
\hline Localización & Titular & Plazas \\
\hline Almería & Don Î́nigo de Guevara & 70 \\
\hline Adra & Don Luis de Valdés & 44 \\
\hline Motril y Almuñécar & Don Luis de Valdivia & 102 \\
\hline Marbella & Don Juan de Alarcón & 14 \\
\hline Fortaleza de Almería & Duque de Maqueda & 30 \\
\hline Presidio de Níjar & Cabo del presidio & 14 \\
\hline Presidio de la villa de Felix & Cabo del presidio & 4 \\
\hline Fortaleza de Salobreña & Don Diego López de Zúñiga (teniente de capitán general de la costa) & 15 \\
\hline \multicolumn{2}{|l|}{ Dotación real } & 293 \\
\hline \multicolumn{2}{|l|}{ Dotación teórica } & 602 \\
\hline \multicolumn{2}{|l|}{ Déficit } & 309 \\
\hline \multicolumn{3}{|c|}{ Cuadrillas y soldados extraordinarios de infantería } \\
\hline Localización & Titular & Plazas \\
\hline Mojácar hasta cabo de Gata & Blas de Martos & 105 \\
\hline $\begin{array}{l}\text { Almería, Roquetas, castillo de } \\
\text { San Pedro, Rodalquilar y Níjar }\end{array}$ & Baltasar Rodríguez & 129 \\
\hline La Rábita (Adra) & --- & 16 \\
\hline Fortaleza de Castel de Ferro & --- & 10 \\
\hline Presidio de Nerja & --- & 18 \\
\hline--- & Pedro de Melgar & 24 \\
\hline Marbella & --- & 7 \\
\hline Fuengirola & --- & 13 \\
\hline Estepona & --- & 16 \\
\hline \multicolumn{2}{|l|}{ Dotación real } & 338 \\
\hline \multicolumn{2}{|l|}{ Dotación teórica } & 475 \\
\hline \multicolumn{2}{|l|}{ Déficit } & 137 \\
\hline \multicolumn{3}{|c|}{ Compañías de jinetes } \\
\hline Localización & Titular & Plazas \\
\hline Almería & Cristóbal Briceño de la Cueva, capitán de guardias viejas de Castilla & 42 \\
\hline Vera y Mojácar & Don Alonso de la Cueva, capitán de guardias viejas de Castilla & 35 \\
\hline Adra, Berja y Dalías & Don Bartolomé de Velasco, capitán de guardias viejas de Castilla & 58 \\
\hline Vélez Málaga & Marqués de Mondéjar, capitán de guardias viejas de Castilla & 56 \\
\hline Almería & Don Ínigo de Guevara & 30 \\
\hline Motril & Don Juan de Agreda & 32 \\
\hline Marbella & Don Juan de Alarcón & 47 \\
\hline Vélez Málaga & Capitán general de la costa & 28 \\
\hline \multicolumn{2}{|l|}{ Dotación real } & 339 \\
\hline \multicolumn{2}{|l|}{ Dotación teórica } & 523 \\
\hline \multicolumn{2}{|l|}{ Déficit } & 184 \\
\hline
\end{tabular}




\begin{tabular}{|c|c|c|}
\hline \multicolumn{3}{|c|}{ Fortalezas de la costa } \\
\hline Localización & Titular & Plazas \\
\hline Mojácar & Marqués del Carpio, sirve un teniente & 1 \\
\hline Almería & Duque de Maqueda, sirve un teniente, sin peones & 1 \\
\hline Adra & Francisco de Molina, sirve un teniente & 1 \\
\hline Salobreña & Diego López de Zúñiga, sirve un teniente & 1 \\
\hline Almuñécar & Don Pedro Venegas, sirve un teniente & 1 \\
\hline Vélez Málaga & Pedro Ortiz de Ogaleño & 1 \\
\hline Nerja & Alonso Millán, no sirven él ni teniente & - \\
\hline Málaga & Marqués de Ardales, sirve un teniente & 1 \\
\hline Fuengirola & Capitán Pedro Rodríguez Santisteban, no sirven él ni teniente & - \\
\hline Marbella & Marqués de Ardales, sirve un teniente & 1 \\
\hline Estepona & Capitán Berenguer Cancer & 1 \\
\hline \multicolumn{2}{|l|}{ Dotación real } & 9 \\
\hline \multicolumn{2}{|c|}{ Dotación teórica } & 11 \\
\hline \multicolumn{2}{|l|}{ Déficit } & 2 \\
\hline \multicolumn{3}{|c|}{ Capitán general de la costa, oficiales, entretenidos y alabarderos de escolta } \\
\hline \multicolumn{2}{|c|}{ Capitán general y su teniente } & 2 \\
\hline \multicolumn{2}{|c|}{ Veedor Miguel Montero } & 1 \\
\hline \multicolumn{2}{|c|}{ Veedor don Íñigo Briceño de la Cueva } & 1 \\
\hline \multicolumn{2}{|c|}{ Contador don Joseph Pérez de la Parra } & 1 \\
\hline \multicolumn{2}{|c|}{ Don Pedro de Velasco, entretenido } & 1 \\
\hline \multicolumn{2}{|c|}{ Capitán don Cristóbal Dueñas, entretenido } & 1 \\
\hline \multicolumn{2}{|c|}{ Alférez Alonso de Paterna, entretenido } & 1 \\
\hline \multicolumn{2}{|c|}{ Pagador Alonso Delgado de Mata } & 1 \\
\hline \multicolumn{2}{|c|}{ Alabarderos de escolta del capitán general } & 12 \\
\hline \multicolumn{2}{|l|}{ Dotación real } & 21 \\
\hline \multicolumn{2}{|c|}{ Dotación teórica } & 23 \\
\hline \multicolumn{2}{|l|}{ Déficit } & 2 \\
\hline \multicolumn{2}{|l|}{ DOTACIÓN REAL } & 1.272 \\
\hline \multicolumn{2}{|c|}{ DOTACIÓN TEÓRICA } & 1.930 \\
\hline \multicolumn{2}{|l|}{ DÉFICIT } & 654 \\
\hline
\end{tabular}

Fuente: elaboración propia a partir de una relación de los veedores y contador del sueldo de la gente de guerra de la costa del reino de Granada, de 22/01/1602, referida al contingente real en el último cuatrimestre de 1601 . Archivo General de Simancas (en adelante AGS), Guerra Antigua, leg. 600, f. 154. Esta información se complementa con datos de AGS, Guerra Antigua, Servicios Militares, leg. 84, f. 58. 
Como puede observarse, la mayor concentración de guardas de costa, fuerzas de infantería, caballería y cuadrillas se producía en el área de levante, que comprendía los distritos defensivos de Adra, Almería y Vera-Mojácar, una franja costera de unas 35 leguas aproximadamente, que había sufrido con mayor virulencia el proceso de despoblación subsiguiente a la expulsión morisca. La parte del contingente militar con mayor déficit de hombres sobre las dotaciones teóricas eran las fuerzas de las cuadrillas de presidios y las compañías de infantería y caballería, que estaban destacadas en las cabezas de los distritos defensivos. Precisamente, aquellas que ejercían el papel más importante y activo en las tareas de defensa frente a las incursiones de enemigos en la costa, muy especialmente en el sector oriental del reino, fuertemente despoblado desde la expulsión de los naturales. Este comprendía desde Adra, pasando por la accidentada zona del cabo de Gata, hasta la frontera con el reino de Murcia.

La tabla también refleja quiénes eran los oficiales en un organigrama, el del gobierno militar del territorio, que se había simplificado enormemente desde la expulsión de los moriscos. Por un lado, dos veedores, uno para el distrito oriental, don Íñigo Briceño de la Cueva, situado en la ciudad de Almería y que comprendía el área entre Adra, y Vera-Mojácar; y otro para el distrito de poniente, con residencia en Vélez Málaga - Miguel Montero-, que se ocupaba del sector que iba desde Marbella a Motril. Ambos veedores debían evitar que se cometiesen fraudes en los procesos de revista, alarde y paga de la soldadesca, obrando en su poder un libro de cuenta y razón, donde tomaban copia de los alardes o listas elaboradas por los contadores de cada compañía o escuadra, a fin de registrar todas las incidencias. Sus libros tenían que ser cotejados con el del contador y debían realizar las averiguaciones oportunas para verificar que todo se ajustaba a las ordenanzas de las guardas. Acto seguido, se firmaban los alardes junto con el contador y el oficial de cada compañía, base sobre la que se elaboraban las nóminas. Posteriormente, el veedor debía también estar presente en los socorros y pagas para evitar la comisión de posibles fraudes, faltas con o sin licencia, a fin de dar el refrendo a los libros de los contadores para que estos pudiesen realizar las pagas ${ }^{3}$.

Destaca también la figura del contador general del sueldo, don Joseph Pérez de la Parra, que venía ejerciendo el cargo desde 1591, fecha en que se instauró dicho oficio, con motivo del descubrimiento de un fraude importante en la pagaduría de Blas de Torres y de su hijo Juan de Torres (Jiménez Estrella, 2004, p. 235 y ss.). Pérez de la Parra debía acompañar al capitán general de la costa con libro de cuenta y razón. En este se debía registrar el cargo y la data del pagador, para llevar un control

3 Un ejemplo de las competencias fijadas en las provisiones de nombramiento en este período, en AGS, Guerra Antigua, lib. 102, f. 61v-62v. (nombramiento de Juan Herrera como veedor del partido de levante en 28 de enero de 1608). 
exhaustivo de ingresos y libranzas, así como de la gestión del proveedor de bastimentos. Actuaba también un pagador general de la gente de guerra del reino, Alonso Delgado de Mata, quien ejercía el oficio desde 1593. Tenía a su cargo los gastos de fábrica y conservación de las torres y fortalezas del litoral y las libranzas del sueldo de todo el personal del sistema defensivo con cargo a la consignación de los 80.000 ducados ${ }^{4}$, incluida la guarnición de 80 soldados de la Alhambra, pagada aparte del resto de personal militar.

Al frente de todo el sistema defensivo estaba el capitán general de la costa, máximo mando e instancia jurisdiccional sobre los territorios que, desde la expulsión morisca, el ostracismo de los Mendoza y la remodelación de la Capitanía en 1574, comprendían el distrito militar de la costa del reino de Granada. Sus atribuciones se desplegaban sobre todo el personal castrense del territorio y aquellas compañías y fuerzas militares que estuviesen de paso para embarcarse en el puerto de Málaga a otros destinos. Al respecto, conviene advertir de la pérdida de competencias experimentada por el capitán general durante el último cuarto del XVI. La nueva denominación dada al cargo a partir de 1574 y el conjunto de instrucciones promulgadas entonces determinaron cambios importantes en el órgano. Buena parte de sus atribuciones y el ejercicio de su jurisdicción quedaron reducidos al marco costero y sin competencia directa sobre la administración y mando de la fortaleza de la Alhambra y su guarnición. Durante más de setenta años, el palacio nazarí había sido la sede y el centro neurálgico del poder militar y político de los Mendoza durante el «tiempo morisco» (Jiménez Estrella, 2009). A ello se sumaba también el desplazamiento o «marginación litoral» de la sede y residencia de los capitanes generales a Vélez Málaga, ciudad mucho menos relevante que Granada, lo cual revestía también una importante carga simbólica (Jiménez Estrella, 2004, p. 205 y ss.).

Este proceso, gestado durante el último cuarto del siglo XVI, se consolida durante el reinado de Felipe III, en que los nuevos titulares del cargo presentan un perfil institucional mucho más bajo. De miembros de la alta aristocracia castellana, con dilatados servicios y presencia en los principales órganos de gobierno de la monarquía, a militares veteranos y oficiales de la administración castrense, que ven en el cargo un importante ascenso en el escalafón y en la pirámide social, dado el carácter honorífico del oficio y su sueldo -2.000 ducados anuales - . De representantes del poder regio con atribuciones cuasi-virreinales, intermediarios con los moriscos y actores políticos de primer nivel en el gobierno del reino, con importantes vínculos y apoyos en la corte, a meros gobernadores militares con potestad de mando estrictamente reducida al personal militar de la costa. De participar durante mucho tiempo en el reparto de las fardas y servicios moriscos, con los que se pagaba la defensa del territorio, a no tener 
ningún tipo de intervención sobre el sistema de reparto fiscal y financiación con el que se sostenía el dispositivo defensivo, que dependía enteramente de una Junta de Población en la que el capitán general no tenía presencia alguna (Birriel Salcedo, 1995).

Otro rasgo a destacar es la situación de interinidad en que quedó el cargo durante buena parte de este período. Hasta mediados de septiembre de 1607, fecha de su muerte ${ }^{5}$, el capitán general de la costa fue don Hernando Hurtado de Mendoza — hidalgo de Miranda de Ebro, sin parentesco con los marqueses de Mondéjar-. Este veterano oficial de la administración castrense, que años antes de su nombramiento había desempeñado el cargo de gobernador militar ${ }^{6}$ y en 1588 había sido destinado a la Capitanía General de Guipúzcoa y Fuenterrabía ${ }^{7}$, fue nombrado capitán general en octubre de $1590^{8}$. Hurtado de Mendoza fue asistido en su oficio por un teniente de capitán general, el soldado veterano de la guerra de las Alpujarras y caballero de Santiago don Diego López de Zúñiga ${ }^{9}$. Éste tenía potestad para ejercer sus competencias especialmente en el sector oriental del reino, donde Hurtado de Mendoza no solía estar presente ${ }^{10}$. Durante este tiempo, López de Zúñiga trató de conseguir una subida en el sueldo de 480 escudos que percibía, parcialmente satisfecha con la concesión en 1593 de una ayuda de costa de 100 ducados anuales ${ }^{11} \mathrm{y}$, mucho más importante, la alcaidía de la fortaleza de Salobreña tres años después ${ }^{12}$.

A su muerte en agosto de 1607, Hurtado de Mendoza fue sustituido por López de Zúñiga, dado que era el candidato con más experiencia y conocimiento sobre el funcionamiento del dispositivo militar ${ }^{13}$. Sin embargo, sus aspiraciones no fueron colmadas, pues nunca llegaría a obtener nombramiento de capitán general de la costa. Se produjo a partir de entonces un largo período interinidad en el cargo, que poco tenía que ver con la realidad militar y defensiva del reino y mucho con la política de adquisición y acaparamiento de prebendas, mercedes y fuentes de ingresos en manos del duque de Lerma (García García, 2012). A mediados de 1608, Lerma sumaba a sus muchos títulos y cargos el de capitán general de la costa del reino de Granada, a lo

5 Don Hernando hizo testamento en Vélez Málaga el 16 de septiembre de 1607, instituyendo como heredera universal a su hija doña María Hurtado de Mendoza, falleciendo el día siguiente, Archivo Histórico de la Nobleza, Baena, C. 346, D. 170.

6 Ejerció el cargo entre abril de 1583 y octubre de 1588, cobrando la mitad del sueldo -1.000 ducados anuales- y sin llegar a ser nombrado capitán general de la costa: AGS, Contaduría del sueldo, $2^{\mathrm{a}}$ Serie, leg. 234, sf.. AGS, Guerra Antigua, leg. 217, f. 44. AGS, Guerra Antigua, leg. 208, f. 110.

$7 \quad$ AGS, Guerra Antigua, lib. 37, f. 8r.

8 AGS, Guerra Antigua, leg. 298, f. 116.

9 AGS, Guerra Antigua, lib. 126, f. 89r-v.

10 AGS, Guerra Antigua, lib. 37, f. 11v.

11 AGS, Guerra Antigua, leg. 503, f. 325.

12 AGS, Contaduría del Sueldo, $2^{\mathrm{a}}$ Serie, leg. 378, sf. El cargo comportaba la obligación de mantener 14 soldados en el castillo y la percepción de un sueldo de 666,66 ducados anuales, que cobraría a pesar de un prolongado absentismo que justificaba en sus deberes como teniente de capitán general. AGS, Guerra Antigua, lib. 91, f. 37r-v. AGS, Guerra Antigua, lib. 102, f. 12v-13r. 
que se añadía el hecho de que su hijo, el duque de Cea, venía disfrutando desde 1604 de la alcaidía de la Alhambra, que hasta esa fecha había estado en manos de los Mendoza (Jiménez Estrella, 2000). Obviamente, ni Lerma ni Cea conocían nada sobre el gobierno militar o la realidad política del reino granadino y solo se preocuparon por el cobro de los sueldos de unos cargos en los que practicaron el más absoluto absentismo. Lerma delegó sus competencias en López de Zúñiga como teniente de capitán general y en septiembre de 1610 decidió dividir el distrito defensivo de la costa en dos partidos: uno en poniente, con sede en Vélez Málaga, donde debía residir Zúñiga como teniente de capitán general; y otro en levante, con sede en Almería, y a cargo del antiguo veedor, capitán de guardias viejas de Castilla y caballero de Santiago don Íñigo Briceño de la Cueva ${ }^{14}$, bajo las órdenes del teniente de capitán general ${ }^{15}$.

A fines de febrero de 1611, el duque de Lerma decidió dejar los cargos de capitán general de caballería de España y de la costa del reino de Granada ${ }^{16}$. Diego López de Zúñiga solicitó entonces que se le premiase con la titularidad del cargo y se le otorgase la alcaidía de Salobreña por dos vidas más. A pesar de que era apoyado en sus pretensiones por el consejo de Guerra ${ }^{17}$, Zúñiga solo consiguió la merced de la alcaidía y un incremento de su sueldo en 600 ducados más ${ }^{18}$. Casi se equiparaba su salario al del capitán general —unos 1.800 ducados_-, se le otorgaban competencias, preeminencias y atribuciones muy similares y la capacidad de despachar directamente con el consejo de Guerra. Sin embargo, solo se le dio título de «gobernador de la gente de guerra de a pie y a caballo» de la costa, oficio de rango inferior al que Zúñiga pretendía ${ }^{19}$. En octubre de 1614, debido a su avanzada edad y mal estado de salud $^{20}$, comenzó un largo período de ausencias en el cargo ${ }^{21}$, durante el cual don Ínigo Briceño asumiría el mando y gobierno de todo el sistema defensivo, hasta su nombramiento definitivo a mediados de 1619 como nuevo gobernador de la gente

14 Don Íñigo actuó como veedor de la gente de guerra entre 1590 y 1607. Entonces fue nombrado capitán de una compañía de guardias viejas, precisamente, en sustitución de su hermano Cristóbal, muerto durante una escaramuza en la costa. Don Íñigo vinculó su carrera de ascenso social al desempeño de cargos y oficios de mayor relevancia en la administración militar granadina -a partir de 1614 será teniente de capitán general y desde 1619 gobernador de la gente de guerra- y a la consecución de sus pretensiones de ennoblecimiento. Primero, con la adquisición del hábito de Santiago en 1610 (Archivo Histórico Nacional, Órdenes Militares, Santiago, Exp. 1.238). Segundo y más importante, mediante la compra del señorío de Torres de Alicún en 1614 por 3.200 ducados (Soria Mesa, 1995, pp. 118 y 151).

15 AGS, Guerra Antigua, lib. 107, f. 331v-332r

16 La dejación de ambos cargos se hacía bajo la fórmula «en tiempo de paz». AGS, Guerra Antigua, lib. 111, f. 40

17 Consulta del consejo de Guerra de 12/03/1611, AGS, Guerra Antigua, leg. 744, sf.

18 AGS, Guerra Antigua, lib. 111, f. 39r.

19 Provisión de 16/11/1611, AGS, Guerra Antigua, lib. 111, f. 40.

20 AGS, Guerra Antigua, lib. 119, f. 2 v.

21 Obtuvo durante dicho período sucesivas licencias para ausentarse del cargo, no solo por sus achaques y enfermedad, también para resolver negocios de su casa. AGS, Guerra Antigua, lib. 119, f. 173v-174r., 353r. 
de guerra de la $\operatorname{costa}^{22}$. Así pues, con don Íñigo, que estaría al frente de la defensa costera hasta su muerte en $1629^{23}$, se perpetuaba el mismo esquema orgánico de una Capitanía General sin proveer o en manos de un aristócrata absentista, con uno o dos tenientes encargados de la gobernación militar del territorio y que, de hecho, ejercían sus funciones con un perfil institucional inferior. Lo cual venía a consolidar un proceso gestado desde tiempo atrás: la devaluación política, simbólica e institucional del oficio y su reducción a una de las muchas mercedes y pensiones en manos de representantes de la alta nobleza y miembros de la corte, puesto que el modelo de capitán general absentista se iba a repetir bajo Felipe IV, nada menos que en la figura del conde-duque de Olivares ${ }^{24}$.

Durante los años que ejercieron el oficio, Mendoza, Zúñiga y Briceño actuaron como la máxima autoridad militar con mando y jurisdicción privativa sobre todo el personal del sistema defensivo. También con otras atribuciones que concernían a los procesos de abastecimiento de la tropa, como la potestad de nombrar jueces comisionados para embargar trigo y cebada para el aprovisionamiento del personal militar de la costa en aquellos lugares de los reinos de Murcia, Granada y Andalucía que se encontrasen dentro de las 24 leguas de la costa ${ }^{25}$. No obstante, mantuvieron también litispendencia con otros órganos jurisdiccionales como la Chancillería de Granada o algunos corregidores. Es cierto que este tipo de conflictos de competencias y jurisdicción formaron parte de la realidad institucional del Antiguo Régimen y habían sido algo usual durante el siglo xvi. Por esta razón la corona tuvo que promulgar varias pragmáticas y concordias que confirmaban las competencias del capitán general en materia de fuero militar (Jiménez Estrella, 2004, pp. 250-273). Sin embargo, con frecuencia escondieron un pulso institucional y un intento de menoscabo en sus competencias y atribuciones de mando y jurisdicción en el territorio, muy especialmente en sus disputas con los corregidores de Málaga, Ronda y Marbella, que ejercían también funciones de capitanes a guerra y no veían con buenos ojos el parapeto que el fuero privativo otorgaba al personal militar frente a la población civil.

Algunos ejemplos son bastante ilustrativos. A mediados de septiembre de 1598, el corregidor de Ronda y Marbella, don Alonso García Valdeón, pretendía juzgar y condenar a tres soldados de la compañía de don Juan de Alarcón que habían cometido un delito contra vecinos de Marbella. El corregidor se escudó en su potestad como capitán a guerra y superintendente del rey y en la condición los encausados de vecinos

22 AGS, Guerra Antigua, lib. 126, f. 136v-137v.

23 AGS, Guerra Antigua, leg. 1.122, sf.

24 Olivares, como capitán general de caballería de España, ostentaba título de capitán general de la costa del reino de Granada, AGS, Guerra Antigua, leg. 993, sf.

25 Así se dispone, por ejemplo, en reales cédulas de 22/05/1599 (AGS, Guerra Antigua, leg. 565, f. 361) y 14/06/1601 (AGS, Guerra Antigua, lib. 91, f. 58r-59r.), confirmadas en años sucesivos. 
del lugar y, por tanto, bajo su jurisdicción ${ }^{26}$. Sin embargo, desde Madrid se recordó al corregidor que este tipo de causas competían exclusivamente al capitán general ${ }^{27}$. En junio de 1601, Felipe III volvía a reforzar la autoridad Hurtado de Mendoza, a propósito de un nuevo conflicto con el alcalde mayor de Almuñécar, por la detención de un soldado de la compañía de Luis de Valdivia ${ }^{28}$. En agosto de ese mismo año, se confirmaba una real cédula anterior sobre las competencias jurisdiccionales del capitán general $^{29}$ y en agosto de 1612 volvía a registrarse un pleito entre el alcalde mayor de Motril y don Diego López de Zúñiga, como consecuencia de un enfrentamiento entre los oficiales de las compañías de la villa y algunos regidores sobre el conocimiento de causas que concernían a los soldados de sus unidades ${ }^{30}$. Este tipo de tensión jurisdiccional formó parte del día a día de la soldadesca, pues el personal militar se acogía al fuero castrense. Razón por la cual, como exponía en mayo de 1620 don Íñigo Briceño al consejo de Guerra, recibían vejaciones de las justicias ordinarias «por el odio que tienen a la dicha gente de guerra, por no ser de su jurisdicción ni poder tener della el aprovechamiento que de los demás vecinos sacan injustamente ${ }^{31}$. Obviamente, las palabras del gobernador militar nos brindan solo la versión de una parte del conflicto. Asimismo, dejan entrever un problema que iba mucho más allá del choque de competencias, para adentrarse en una cuestión aún más espinosa que, como ha destacado Susana Truchuelo, está vinculada a la conflictividad generada por las relaciones entre civiles y militares en el mundo urbano fronterizo (Truchuelo García, 2012).

Una de esas esferas de disputa fue el reparto de presas por captura de moros, parte esencial de los rebatos y cabalgadas en la costa cuando había alertas de enemigos. La corona, consciente del bajo sueldo de los integrantes del sistema defensivo, trató de incentivarlos, incluyendo una exención del pago del quinto que pertenecía al rey en cualquier captura de presas y cuyo reparto correspondía, en última instancia, al capitán general o al gobernador de la costa. El reparto de presas fue un aspecto clave que caracterizó la vida en la frontera marítima granadina y una de las fuentes de litigio y enfrentamiento más importantes entre los vecinos del litoral y el personal militar profesional. Generó toda una economía en torno a la captura, reparto y puesta en almoneda de esclavos musulmanes de origen norteafricano, que suponían una importante fuente de ingresos y todo un sector económico de capital importancia en enclaves como la ciudad de Almería y, muy especialmente, Málaga, que actuaba como el gran centro redistribuidor de esclavos en el reino de Granada (González Arévalo, 2014 y Andújar Castillo, 1992-93). Por ejemplo, en septiembre de 1602 volvía

26 AGS, Guerra Antigua, leg. 519, f. 104 y 105.

27 AGS, Guerra Antigua, leg. 524, f. 264.

28 AGS, Guerra Antigua, lib. 91, f. 66v-70r.

29 La orden confirmada era de 1593, AGS, Guerra Antigua, lib. 91, f. 85r-86v.

30 Real Cédula de 1/08/1612 al alcalde mayor de Motril. AGS, Guerra Antigua, lib. 114, f. 7v-8r.

31 Consulta del consejo de Guerra de 22 de mayo de 1620. AGS, Guerra Antigua, leg. 862, sf. 
a producirse un pleito entre el capitán general y el corregidor de Ronda y Marbella, con motivo de una disputa con el alférez de la compañía de don Juan de Alarcón sobre un reparto de moros capturados en Estepona ${ }^{32}$, y en agosto de 1612, el corregidor de Málaga don Jerónimo de Santa Cruz mantenía otro conflicto de competencias con Diego López de Zúñiga, a propósito del enfrentamiento entre el alférez Juan Gómez y el alcalde ordinario de Mijas por la negativa del último a entregarle un turco que había desembarcado junto a otros cuatro en Fuengirola ${ }^{33}$. Este tipo de pleitos nos muestran cómo numerosos oficiales y soldados eran lugareños y sus vidas y sus intereses se desarrollaban en el estrecho marco local, donde muchos de ellos podían incluso ostentar cargos concejiles. La cohabitación de distintos poderes, gobiernos militares, corregidores y alcaldes mayores, cada uno con sus esferas de jurisdicción, generaba tensiones en las que el fuero castrense se consideraba un escudo que los protegía de la acción de las justicias ordinarias y, por tanto, podía distorsionar la vida local en torno a un juego de intereses políticos y económicos de compleja resolución (Truchuelo García, 2012).

\section{La escalada del corso y la amenaza sobre la frontera marítima}

Los aspectos de orden estructural, institucional, orgánico y jurisdiccional aquí abordados evidencian los cambios operados en el reino y en su posición en el entramado estratégico y militar de la Monarquía Hispánica desde fines del siglo XVI. Sin duda, el único modo de entender cómo se articuló la defensa del territorio es situándola en su contexto, porque el sistema defensivo granadino no era un ente aislado. Su evolución, una parte fundamental de la frontera marítima mediterránea, debe enmarcarse en la situación general de la política exterior desarrollada por la monarquía en esta época. Cuando Felipe III cerró las paces con las potencias europeas del norte, recuperó el Mediterráneo como área estratégica, algo que se había puesto de manifiesto con los intentos - no exitosos - de organizar una expedición sobre Argel en 1601 y 1603, (Bunes Ibarra, 2006). A partir de entonces, el nuevo monarca intervendría decididamente en el área, con campañas como la toma de Larache en 1610 y La Mamora en $1614^{34}$, la búsqueda de pactos y un acercamiento con los enemigos

32 Diego Castro Mendoza, corregidor de Ronda y Marbella, fue desautorizado por el consejo de Guerra. AGS, Guerra Antigua, lib. 91, f. 259v-260r y 293v-294r.

33 El corregidor pretendía que, como capitán a guerra, le correspondía la jurisdicción de la causa. Desde el consejo de Guerra se le ordenó inhibirse de ella y entregar el turco capturado, so pena de 30.000 maravedís. AGS, GA, lib. 114, f. 20r-21r.

34 No en vano, con motivo de esta expedición, Medinasidonia requirió el socorro de compañías de milicias de Andalucía. Granada envió siete compañías hasta Pedrera, desde donde volvieron, ya que no era necesaria su participación en la campaña (Henríquez de Jorquera, II, p. 595). 
del Imperio Otomano - persas y griegos, entre otros - y el desarrollo de una nueva política en la que se mostraba como el verdadero garante y campeón del catolicismo frente a los otomanos y sus aliados norteafricanos (Alonso Acero, 1997, pp. 26-56; Bunes Ibarra, 2015). Todo ello tuvo repercusiones muy importantes sobre la frontera marítima del reino granadino.

Amén de la intensificación del tráfico de víveres, provisiones y hombres con los presidios norteafricanos desde la Proveeduría General de Armadas malagueña, la consecuencia más importante fue el notable aumento del corso y la piratería de muy distinto signo, pero especialmente de bandera turco-berberisca, en todo el litoral del levante y sur peninsular ${ }^{35}$. Ello se vio facilitado por la extensa red de información provocada por la diáspora de moriscos expulsos en 1609-14. Estos contaban con datos muy precisos sobre el modo en que se articulaba la defensa costera, las villas del litoral donde residían núcleos importantes de cristianos viejos y los puntos débiles del sistema, al objeto de facilitar los asaltos y la captura de presas para su secuestro y posterior cobro de rescate. Un testimonio revelador de esta realidad es la carta remitida por la ciudad de Almería al rey en octubre de 1600, en la que alega no poder responder a la campaña de reclutamiento del Adelantado de Castilla para la formación de una nueva armada, debido a:

la ruina en que ha venido por la poca vecindad que tiene y el peligro en que está, y que se va despoblando, aviendo costado tanto a Vuestra Majestad, y aunque de nuestra parte se a procurado su aumento, no pasa adelante, y si Vuestra Majestad no lo manda remediar haciendo nuevas mercedes a los vecinos de ella, en breve tiempo se despoblará, por no ser tierra de comarca ni trato que oy no quedan en ella quinientos vecinos. Los trescientos ganan sueldo en la infantería y caballería y guardas que en ella residen, los demás son clérigos y oficiales menesterosos en la república, gente impedida y viejos, los quales an acudido y acuden a la guardia y defensa della, derramando su sangre, que son pocos a quien esto o cautiverios no les toca. La falta de gente que en ella ay es grande para coger los frutos, y muchos años se pierden gran parte dellos, porque no vienen trabajadores de otras partes y por esta causa nadie se anima a plantar los campos, de que gran daño viene al patrimonio real, particularmente en la cría de la seda ${ }^{36}$.

Ciertamente, este tipo de testimonios deben ser tomados con cuidado, pues era tónica general que las ciudades interpusiesen toda suerte de resistencia y trabas, y mostrasen una realidad marcada por la miseria, la pérdida de brazos y la

Sobre esta cuestión hay que destacar, para una perspectiva general y de carácter conceptual, los trabajos de Fontenay, 1984 y Barrio Gozalo, 2006. El caso específico del incremento del corso y la piratería inglesa y holandesa, así como su colaboración con el corso tradicional de bandera musulmana, ha sido bien estudiado por Alonso Acero (1999) y Velasco Hernández (2011). 
penuria fiscal cuando de levas se trataba. No obstante, este fragmento confirma la información que tenemos sobre la situación de despoblamiento que desde la expulsión de los moriscos granadinos había sufrido el área oriental del reino granadino, lo cual tenía repercusiones de importancia sobre la economía, pero también sobre la defensa del territorio. Ante el incremento de las incursiones costeras, la única respuesta arbitrada por los lugareños y las unidades militares de los distritos defensivos eran las llamadas a rebato, protagonizadas fundamentalmente por compañías de jinetes, que podían ser auxiliadas por tropas concejiles. Su éxito era directamente proporcional al nivel de eficacia que las guardas y centinelas de las torres vigía demostraban a la hora de dar las alertas. En caso de ausencia de los puestos o falta de coordinación, como solía suceder con frecuencia, el aviso llegaba demasiado tarde, las compañías de defensa no podían acudir a tiempo y el saqueo dejaba un balance de villas y lugares arrasados y la captura de un botín humano que posteriormente sería objeto de negociación para el pago de su rescate, ya en la misma costa, ya en Argel.

Una prueba más que ilustrativa de esta realidad y de la importante escalada que experimentaron el corso y la piratería durante el reinado de Felipe III, es la proliferación de avisos y relaciones remitidas por los capitanes generales sobre el avistamiento de naves enemigas que se acercaban peligrosamente a la costa para realizar un ataque o que habían protagonizado algún tipo de escaramuza con otras embarcaciones. Un rastreo sistemático de la documentación de las secretarías del consejo de Guerra permite constatar que en este período los avisos se erigieron en un verdadero «género documental» que nos describe a la perfección el grado de presencia del corso de bandera islámica en la zona. En agosto de 1602 el corregidor de Málaga advertía de la necesidad de que las galeras de España no dejasen desamparado el litoral malagueño, pues con la seguridad que los corsarios tenían de que no había galeras en la costa, la corrían de día y de noche. Entonces, nueve galeras desembarcaron 600 turcos en Benagalbón — Rincón de la Victoria—, lugar de 50 casas, donde hicieron algunos cautivos, para desembarcar posteriormente, de madrugada, junto a Benalmádena, donde las llamadas a rebato causaron efecto ${ }^{37}$.

A principios de agosto de 1608 la ciudad de Almería pretendía ante el rey que allí residiese permanentemente un teniente de capitán general — como de hecho se dispondría a partir de 1610 - , alegando ser «la fuerza principal deste reyno para resistir los rebatos de enemigos». Se habían avistado dos galeotas de Argel en las inmediaciones del cabo de Gata y estas habían tomado diez navíos mercantes y habían robado ganado en la zona $^{38}$.

37 Carta del corregidor de Málaga al rey, de 14 de agosto de 1602. AGS, Guerra Antigua, leg. 600, f. 172 
A mediados de febrero de 1615, el teniente del castillo de Marbella, Alonso de Figueroa, informaba de la presencia de numerosos navíos de corso en la costa malagueña. En su carta al consejo, se quejaba de que la falta de artillería en el castillo dificultaba las posibilidades de contrarrestar los ataques sobre los enclaves costeros y las naves mercantes ${ }^{39}$. No en vano, once días antes de su misiva, dos navíos franceses fueron atacados sin que se pudiese hacer nada, y nueve barcos cargados con vino para aprovisionar Orán habían caído en manos de los corsarios. El testimonio del teniente de Marbella es bastante esclarecedor de las consecuencias que el corso norteafricano podía tener sobre los intereses comerciales de las elites mercantiles malagueñas. Como apuntaba Figueroa, era preciso remediar esta situación, pues la hacienda de los malagueños «no vale nada, faltando el comercio della, que sin duda faltará, pues oy no se halla un navío de flete por ningún dinero ni quien asegure las mercaderías por ningún precio ${ }^{40}$. En septiembre de 1616 , el batallón de milicias de Granada, instaurado solo cuatro años antes, fue movilizado para acudir en defensa de Motril y Almuñécar, debido al avistamiento de 40 navíos turcos. Pasado el peligro, en el valle de Lecrín, vía de acceso natural de Granada a la costa, las compañías fueron desmovilizadas (Henríquez de Jorquera, II, p. 608).

Las noticias sobre el aumento del corso se intensificaron en años posteriores, hasta el punto de que entre 1617 y fines de 1618, desde la corte hubo algún proyecto para realizar una expedición, finalmente abortada, sobre Argel, principal base de operaciones del corso y el tráfico de cautivos cristianos en el Mediterráneo (Bunes Ibarra, 2016). En mayo de 1617, un motrileño allí cautivo alertaba al capitán de compañía de Motril de la presencia de cerca de 200 naves preparadas para salir del puerto argelino, de las que cuatro fragatas y cuatro galeras se iban a dirigir al cabo de $\mathrm{Gata}^{41}$. Solo tres meses después, el alcalde mayor de Motril avisaba de la persecución sufrida por cinco embarcaciones de ingleses y flamencos a manos de veinticinco navíos de bandera turca, que poco después se avistaban a la altura de La Herradura, dispuestos a hacerse con cautivos ${ }^{42}$. Con motivo de estos avistamientos, a inicios de agosto de ese mismo año, el corregidor de Granada y el presidente de la Chancillería mostraban su preocupación por la escalada del corso en las costas granadinas. Frente a ellas se habían apostado tres escuadras con más de cincuenta embarcaciones enemigas que, a su juicio, no intentarían tomar tierra, «contentos con lo que roban por la mar como quienes andan señores de ella ${ }^{43}$. Estas escuadras hicieron saltar las alarmas entre las

39 AGS, Guerra Antigua, leg. 804, sf.

40 AGS, Guerra Antigua, leg. 804, sf.

41 Carta al capitán Juan Corella de Agreda, con fecha 22 de mayo de 1617. AGS, Guerra Antigua, leg. 822, sf.

42 Don Luis Vázquez de Guzmán al secretario del consejo de Guerra, 7 de julio de 1617. AGS, Guerra Antigua, leg. 822, sf.

43 Carta del presidente de la Chancillería al consejo de Guerra, de 7 de agosto de 1617. AGS, Guerra Antigua, leg. 817, sf. 
localidades costeras y la ciudad de Granada, cuya milicia concejil estaba preparada para salir en auxilio de Motril y las localidades comarcanas ${ }^{44}$.

El consejo de Guerra advertía entonces de ello y del peligro que acechaba a los buques mercantes y puertos del sur peninsular, cuya seguridad era fundamental. Por ello, era preciso reforzar la Armada del Mar Océano, al objeto de intensificar la respuesta al corso y asegurar también la Flota de Indias. Esta última advertencia llamaba la atención sobre la necesidad de establecer lazos y una coordinación entre los dos sistemas de defensa navales habilitados al sur de la Península: las Galeras de España, que cubrían los sistemas de transporte y provisión de víveres, armas, municiones y hombres para los presidios norteafricanos y las posesiones italianas, y la Armada del Mar Océano, cuyo marco de actuación, bajo la dirección del duque de Medinasidonia, cubría desde el Estrecho de Gibraltar hasta el cabo de San Vicente, así como las posesiones norteafricanas de la monarquía en la fachada atlántica (Salas Almela, 2002).

A mediados de abril de 1618, don Íñigo Briceño de la Cueva, gobernador de la gente de guerra, remitía nuevos avisos sobre la presencia de más de treinta navíos norteafricanos que habían protagonizado persecuciones sobre embarcaciones mercantes francesas y flamencas, desde las costas del cabo de Gata, pasando por Adra, Castel de Ferro, Motril y Vélez Málaga. Durante su largo periplo, la escuadra fue realizando capturas sobre los mercantes y algunos ataques aislados sobre el litoral, repelidos por la artillería de los fuertes de San Pedro, Castel de Ferro y Salobreña ${ }^{45}$. En julio de 1619 volvía a enviar a la corte una larga lista de avisos sobre la presencia de corsarios y dejaba constancia de numerosos incidentes que afectaban a embarcaciones mercantes asediadas a pocas millas de las costas de Almería y Málaga ${ }^{46}$. Apenas tres meses después, se volvía a avisar del constante asedio de los corsarios norteafricanos a navíos de bandera francesa y flamenca, que andaban «infestando aquella costa» desde finales del mes de septiembre y registraban numerosos incidentes con las autoridades militares de los distritos de Marbella y Motril ${ }^{47}$. A finales de febrero de 1620, el gobernador militar relataba cómo cinco naves norteafricanas capturaban un mercante inglés frente a Guardias Viejas, en el partido de Adra ${ }^{48}$. Dos meses después, cuatro navíos de bandera turca que iban persiguiendo cinco mercantes franceses, atacaban Marbella y mantenían intercambio de fuego artillero con su guarnición defensiva. Entonces, el alcalde mayor informaba de las prevenciones realizadas con

44 Consulta del consejo de Guerra, con fecha 15 de agosto de 1617. AGS, Guerra Antigua, leg. 817, sf.

45 Consulta del consejo de Guerra de 13/05/1618, en la que se da cuenta de los avisos remitidos por don Íñigo Briceño. AGS, Guerra Antigua, leg. 827, sf.

46 Consulta del consejo de Guerra, con fecha 21 de agosto de 1619. AGS, Guerra Antigua, leg. 840, sf.

47 La información concernía a avistamientos de naves enemigas en el partido de Marbella (23 y 26 de septiembre) y en la playa de Motril (27 de septiembre), donde se produjo intercambio de fuego de artillería. AGS, Guerra Antigua, leg. 840, sf. 
motivo del ataque y de que el rebato, prolongado durante un día y medio, había puesto al descubierto la falta de armas y municiones en la localidad ${ }^{49}$. A mediados de mayo, don Íñigo Briceño avisaba de nuevos ataques de galeotas berberiscas sobre el cabo de Gata, la Mesa de Roldán y la torre de Carboneras ${ }^{50}$.

Es cierto que este tipo de avisos y alertas remitidas a la corte deben analizarse con cuidado, porque constituyen solo una de las caras de ese prisma tan complejo que era la defensa del litoral. Dada la fuente de la que emanaban, podían esconder un mensaje interesado y exagerar la realidad, a fin de dejar patente en la corte la falta de efectivos humanos, los problemas de financiación y la mala situación material del cinturón poliorcético. No obstante, el cruce de fuentes y las misivas enviadas por otros miembros de la administración granadina - corregidores, alcaldes mayores, ministros de la Chancillería - evidencia que la amenaza y la escalada del tráfico corsario y los ataques sobre el litoral existieron. Además, los avisos no fueron algo exclusivo de los gobernadores y capitanes generales del reino granadino, sino una práctica plenamente extendida a otros sectores de defensa costera de la monarquía. Por ejemplo, el litoral andaluz, donde el duque de Medinasidonia hacía lo propio a mediados de 1620, ante el avistamiento de varias escuadras que sumaban más de 30 bajeles turcos, en persecución de mercantes holandeses entre las costas de cabo de San Vicente y Faro $^{51}$. En mayo de ese mismo año, a propósito de un nuevo conflicto de competencias con la Chancillería de Granada, el duque refería al consejo de Guerra la situación de desamparo en que se encontraba la costa andaluza ${ }^{52}$.

Prueba fehaciente de esa amenaza real, es el acontecimiento más importante que cerraría el reinado de Felipe III en las costas del reino de Granada: el ataque a la localidad de Adra el 14 de octubre de 1620, a manos de una flotilla de siete naves con 800 turcos y berberiscos que arrasaron la villa, ampliamente analizado en otro $\operatorname{lugar}^{53}$. El asalto provocó una verdadera batería de decretos y órdenes, dirigidos a las poblaciones de la costa a fin de que estuviesen prevenidas y preparadas para realizar rebatos costeros por si se producían nuevos ataques. Entre octubre de 1620 y febrero de 1621 aumentaron exponencialmente las relaciones de avistamiento de naves de bandera turco-berberisca en la franja litoral que iba desde el cabo de Gata

49 El alcalde mayor de Marbella a la corte, a 24 de abril de 1620. AGS, Guerra Antigua, leg. 854, sf.

50 Avisos de don Iñigo Briceño al consejo de Guerra, con fecha 23 de mayo de 1620. AGS, Guerra Antigua, leg. 862, sf.

51 Relación de avisos remitida por el duque de Medinasidonia, de 11 de mayo de 1620. AGS, Guerra Antigua, leg. 854, sf.

52 AGS, GA, leg. 854, sf.

53 Una detallada descripción del ataque, en Sánchez Ramos (2010). Se analizan las consecuencias del asalto, el conjunto de inspecciones y visitas realizadas con motivo del mismo, así como las medidas de protección y movilización de fuerzas milicianas articuladas desde el consejo de Guerra, en Jiménez Estrella (2019). 
hasta Vélez Málaga, donde se encontraba la sede de la Capitanía General ${ }^{54}$. A ello hay que sumar noticias sobre posibles ofensivas a otros núcleos de población, como ponían de manifiesto algunos informantes que conocían los planes de las escuadras argelinas (Jiménez Estrella, 2019, pp. 348-350). No obstante, lo más relevante es que el suceso de Adra puso sobre la mesa importantes problemas estructurales en el sistema defensivo, que venían desde muy atrás y sobre los que es preciso detenernos.

\section{La defensa y sus problemas estructurales}

Uno de los problemas más graves que presentaba el sistema defensivo era el pésimo estado de buena parte de su red de fortalezas y torres vigía, la disminución del número de hombres en la dotación real del cinturón costero y, directamente relacionado con ambas cuestiones, la escasez de recursos y los problemas que arrastraba la consignación para el pago de la gente de guerra. En agosto de 1603, tras una visita exhaustiva al cinturón defensivo, don Hernando Hurtado de Mendoza ya había reclamado más de 20.000 ducados para reparos de fortalezas y torres vigía, y otros 1.500 ducados para dotar de artillería los castillos y presidios del litoral, donde había solo 66 piezas y algo menos de 2.000 balas de distinto calibre ${ }^{55}$. Alertó, asimismo, de la situación de abandono e inasistencia en que se encontraban las torres y estancias de alerta costera, de la enorme despoblación sufrida por Almería y su partido tras la expulsión de los moriscos, del pésimo estado de las murallas de su alcazaba y de las defensas de Vera y Mojácar ${ }^{56}$.

Tres años antes, el consejo de Guerra había propuesto al rey una necesaria subida y equiparación en el sueldo de las ocho plazas de capitanes de infantería y jinetes que residían en Marbella, Motril, Berja, Adra y Almería. La propuesta se había hecho con base en los informes del capitán general de la costa y una relación remitida por él a la corte en octubre de 1600, dado que estos oficiales no habían estado comprendidos

54 En una extensa relación de avisos de 13 de diciembre de 1620, Íñigo Briceño advertía al consejo de Guerra de la presencia, entre el 5 y el 10 de diciembre, de dos navíos de alto bordo y una fragata de moros a vista del cabo de Gata. Estas capturaron un mercante inglés, cuyos tripulantes arribaron a Almería, dando información sobre la salida de una escuadra de galeras de Argel. A fines de diciembre de ese mismo año, una compañía de soldados dio con varios berberiscos cerca de Cala Higuera, de los que mataron a uno y otros quedaron heridos. En otra relación del 17 de enero de 1621, se avisaba de que once días antes, en las inmediaciones del cabo de Gata, se había producido un enfrentamiento entre una escuadra de galeras y un navío musulmán. En días posteriores, varias naves berberiscas atacaban a mercantes flamencos a la altura de Castel de Ferro y seis embarcaciones de bandera musulmana merodeaban la costa de Vélez Málaga. AGS, Guerra Antigua, legs. 854, sf y 873 , sf.

55 AGS, Guerra Antigua, leg. 604, fol. 132.

56 Consulta del consejo de Guerra, de 20 de agosto de 1603. AGS, Guerra Antigua, leg. 604, f. 131. 
en la subida general decretada en $1591^{57}$ y habían perdido una parte importante de su poder adquisitivo. Sin embargo, el plan fue rechazado por el rey, pues «no conviene esto ni hera tiempo para tratar dello, y pesarame mucho de que se entienda que sin orden mía gasta el tiempo el Consejo con estas cosas $\rangle^{58}$.

En mayo de 1603, el capitán general de la costa advertía del desesperado estado en que se encontraba la gente de guerra, siendo una costa abierta de 80 leguas sin apenas guardas, razón por la que volvía a suplicar se remediase esta situación y se subiesen los sueldos de una tropa que debía ser auxiliada con provisiones de trigo y cebada para poder subsistir. El problema debía solucionarse, pues cualquier daño que hiciesen los enemigos sería muy importante,

y causa que se despoblasen los lugares de la mucha población que a tanta costa se an ydo conservando, y oy, por ver las guardas diferentes, dejan de cultivar la tierra y la cría de los ganados, con que pastaban los campos, por la poca seguridad que le parece tendrán. Y aunque acuden a mí y los entretengo y ánimo, no a de bastar [...]. Y juntamente con esto se acaba la más lúcida caballería que aquí a habido nunca y lo que importa para sustentarla ${ }^{59}$.

Lo cierto es que la solicitud de cualquier subida en el salario de la tropa era más voluntarista que realista. Como denunciaban las autoridades militares, el problema más grave era la quiebra de la consignación en la que se cargaba el sueldo de la tropa y las provisiones para abastecer y reparar el sistema defensivo. Como ya se ha señalado, después de la expulsión morisca se habilitó la denominada Renta de Población, con una consignación anual de 80.000 ducados destinados, en teoría, a gastos de defensa. Sin embargo, la realidad era muy distinta. En 1605 el presidente de la Chancillería advertía al consejo de Guerra de que los repobladores del reino pagaban por las haciendas de bienes confiscados algo más de 67.000 ducados de renta, 13.000 menos que lo consignado para la paga de la tropa costera y de la Alhambra. El déficit se debía a la falta de frutos y caudal de los pobladores, de modo que en febrero de 1605 todavía se adeudaban dos tercios de la paga del año anterior ${ }^{60}$. Ese mismo año, el capitán general recordaba que los 80.000 ducados presupuestados no eran suficientes para el pago de sueldos y provisión de trigo y cebada. Más aún, tomando en cuenta la «esterilidad» de los años, que había provocado serios problemas para que los nuevos pobladores pagasen las rentas y censos en que se cargaba la consignación de la gente de guerra. Soslayar este problema suponía dejar la costa desamparada

$57 \quad$ AGS, Guerra Antigua, leg. 570, f. 286.

58 Consulta del consejo, de 20 de agosto de 1600. AGS, Guerra Antigua, leg. 570, f. 55.

59 AGS, Guerra Antigua, leg. 626, f. 65.

60 AGS, Guerra Antigua, leg. 640, f. 61. 
de guardas, soldados y jinetes — sobre todo estos últimos— ${ }^{61}$. Las advertencias del capitán general se sumaban a las del consejo de Guerra, que solicitó al rey el cumplimiento del pago de las soldadas, o al menos se adelantasen 40.000 o $50.000 \mathrm{du}-$ cados para auxiliar a la tropa y, si no era posible que nuevos pobladores sufragasen el sostenimiento del sistema defensivo, se sacase el dinero de otras consignaciones ${ }^{62}$. Estas advertencias volverían a repetirse en septiembre de 1605, cuando el consejo solicitaba al rey el pago de los atrasos acumulados, pues se corría el peligro de que se deshiciese una tropa que «con tanto trabajo y cuidado a costado ponerla en el estado en que se alla, y que por esta causa harán los cosarios muchos daños en la costa, a que Vuestra Majestad en ninguna manera debe dar lugar» ${ }^{63}$.

El máximo órgano militar de la monarquía alertaba en 1609 de que sobre las 1.931 plazas teóricas había solo 1.395, a tenor de una relación remitida por el contador del sueldo. Ese déficit de más de 536 hombres, casi un 30\%, concentraba, como en 1600, sus cifras más importantes en las tropas de infantería ordinaria - 356 sobre 602 de planta - y las compañías de lanzas jinetas - 343 sobre 523-. Como apuntaba el consejo, esto se debía a la falta de pagas y por ello pedía al rey que al menos se librasen los 80.000 ducados asignados y los atrasos acumulados ${ }^{64}$. Solo un año después, Diego López de Zúñiga, teniente de capitán general, volvía a llamar la atención sobre lo escaso de los 80.000 ducados de consignación, con un testimonio que nos describe a la perfección los problemas por los que pasaba la defensa costera y una tropa que:

\begin{abstract}
clama al cielo dando voces por su paga, y que la ha ydo procurando entretener con buenas esperanzas de que VMd se serviría de mandar proveer dinero para ella, pero que ya no tiene palabras ni bastan diligencias para templar su desconsuelo y travaxo, viendo que se dilata un año y otro el remedio, y que así se va deshaciendo aquella gente muy apriesa. Y cada día tendrá peor estado si con mucha brevedad no se le acude, y en particular la caballería, que tanto ha costado sustentarla, por ser tan importante como se sabe para la guardia de aquellas costas, y que se debe considerar que en el tiempo presente es más necesaria que en otro, pues es de creer que los moriscos que pasaron a Berbería como ladinos y platicos de la tierra, han de armar fustas y navíos de alto borde para hacer entrada por aquella parte. Y no habiendo quien les resista y esté a la vista harán todos los daños que quisieren a su salvo, y en particular a la nueva población de aquel reino ${ }^{65}$.
\end{abstract}

61 Carta de Hernando Hurtado de Mendoza, con fecha 23 de febrero de 1605. AGS, Guerra Antigua, leg. 640 , f. 62 .

62 Consultas del consejo de Guerra, de 20 de marzo y 3 de junio de 1605. AGS, Guerra Antigua, leg. 640, f. 59 y 60 .

63 AGS, Guerra Antigua, leg. 640, f. 135

64 Consulta del consejo de Guerra, con fecha 11 de septiembre de 1609. AGS, Guerra Antigua, leg. 713, sf.

65 AGS, Guerra Antigua, leg. 729, sf. 
El consejo se hacía eco de las denuncias del teniente de general y de la enorme quiebra acumulada por la consignación, razón por la cual, como exponía al rey, «la tiene en el miserable estado de necesidad que Diego López de Zúñiga representa». Para evitar esto y conservarla, aconsejaba proveer, a cuenta de lo que se les debía, 30.000 ducados, ordenando librarlos en «parte cierta» y donde se pudiesen cobrar puntualmente, pues de lo contrario «se habrá deshecho y acabado la que hasta ahora se ha entretenido con buenas palabras». La respuesta del rey, en la línea de otras muchas que concernían al pago de la tropa, no podía ser más dilatoria: escribir al presidente de la Chancillería para que informase de dónde procedía la quiebra ${ }^{66}$. Lo cierto es que se sabía perfectamente que la raíz del problema era el mal estado de la consignación que dependía del pago de censos, rentas y frutos de lo confiscado a los moriscos deportados ${ }^{67}$, que no permitía, desde hacía mucho tiempo, satisfacer las pagas de la gente de guerra.

En los años siguientes, la deuda fue creciendo cada vez más. En 1617 superaba los 226.000 ducados $^{68}$ y llegaba a tal extremo que, a mediados de 1618, Íñigo Briceño denunciaba que era imposible, desde hacía seis meses, pagar las raciones mínimas de cebada a la caballería de la costa, corriendo el riesgo de perderla. Si esta fuerza se deshacía, la costa estaría «con el desamparo y riesgo que se dexa entender, siendo como es la más frequentada de enemigos que ay en estos reynos, por la vecindad de Berbería, como se ha representado diversas vezes a Vuestra Majestad» ${ }^{69}$. Al problema de los sueldos se añadía el lamentable estado en que se encontraba el cinturón de fortalezas y torres vigía del litoral granadino. En mayo de 1620, Briceño volvía a recordar la necesidad de proveer un mínimo de 16.000 ducados para poder afrontar las obras de reparación de las fortalezas y torres de la costa ${ }^{70}$. Tres meses después, el consejo de Guerra pedía a Felipe III que se enviasen los 16.000 ducados lo antes posible, pues si no se libraba el dinero, el coste iba a ser mayor y la costa quedaría «sin defensa y expuesta a los ynconvenientes que pueden suceder, habiendo en la mar el mucho número de navíos de corsarios que se sabe que hacen tanto daño y la traen tan inquieta ${ }^{71}$.

Poco tiempo después, tras recibir un nuevo aviso sobre el paso desde Ibiza a las costas del levante peninsular de las embarcaciones turcas que protagonizaron el asalto de Adra, el consejo retomaba sus advertencias ${ }^{72}$. Sabemos que el traumático

66 AGS, Guerra Antigua, leg. 729, sf.

67 Carta de Hernando de Olmedilla al rey sobre este asunto, con fecha 20 de febrero de 1615. AGS, Guerra Antigua, leg. 804, sf.

68 Consulta del consejo de Guerra, de 6 de julio de 1618. AGS, Guerra Antigua, leg. 854, sf.

69 Consulta del consejo de Guerra, de 1 de agosto de 1618. AGS, Guerra Antigua, leg. 827, sf.

70 El gobernador militar advertía de que la dilación en los arreglos había aumentado el nivel de daños y a muchas de las torres vigía no podían acudir las guardas de costa. AGS, Guerra Antigua, leg. 862, sf.

71 Consulta del consejo de Guerra, con fecha 31 de agosto de 1620. AGS, Guerra Antigua, leg. 854, sf. 72 Consulta del consejo de Guerra, de 17 de octubre de 1620. AGS, Guerra Antigua, leg. 854, sf. 
ataque a Adra tuvo como consecuencia más importante el planteamiento de medidas para mejorar la defensa. Estas surgieron a raíz de una serie de visitas por parte de don Ínigo Briceño y el envío de informes sobre el estado de la defensa y sus puntos débiles, en los que se continuaba poniendo el acento en la falta de remesas para las obras de conservación de fortalezas y en el notable incremento de la deuda en la consignación ${ }^{73}$. Las inspecciones de don Íñigo y del sargento mayor de milicias Juan Sánchez de Porras pusieron sobre la mesa buena parte de las debilidades estructurales del sistema, así como la falta de adiestramiento y armamento de las compañías de milicias locales. Los informes elevados al consejo servirían de base para la implementación de importantes reformas que buscaban mejorar la coordinación de las autoridades militares con las milicias, sus procedimientos de entrenamiento y alarde y perfeccionar el sistema de socorro y asistencia que las poblaciones del litoral y de doce leguas al interior debían prestar en caso de rebato. En febrero de 1621, se establecía una nueva instrucción general en la que se recogía un modelo de asistencia y movilización de la población civil, mediante la división de toda la costa del reino en siete partidos o distritos defensivos, con expresión detallada de las alquerías, lugares, villas y ciudades que debían prestar socorro en cada partido ${ }^{74}$. Sin embargo, como en el caso de otros proyectos precedentes, las medidas adoptadas no tuvieron el resultado deseado, debido a factores como la incapacidad de los municipios para pagar el armamento de la población, la falta de coordinación y adiestramiento de los lugareños o la ausencia de incentivos para formar parte de las milicias locales (Jiménez Estrella, 2019, pp. 361-366).

El ataque a la villa de Adra había evidenciado buena parte de aquellos defectos seculares del sistema defensivo que se habían arrastrado desde fines del siglo XVI. Los más importantes afectaban a la red de fortalezas costeras y torres vigía, muy especialmente las del partido de levante, como ponía de manifiesto Briceño de la Cueva en marzo de $1621^{75}$. Briceño volvía a reiterar la desidia de la administración por no haber remitido los 16.000 ducados que se necesitaban para las obras de conservación del cinturón de fortalezas y, lo peor de todo, no se ponía atajo al problema de la deuda del sueldo, que en los meses finales del reinado de Felipe III alcanzaba ya los 400.000 ducados. En los memoriales y relaciones remitidas a la corte eran frecuentes expresiones como «miserable», «extrema necesidad», «peligro de deshacerse», al referirse a la gente de guerra. Formaron parte del lenguaje empleado por los miembros

73 AGS, Guerra Antigua, leg. 854, sf.

74 Los siete distritos o partidos defensivos eran, en dirección este-oeste: Vera-Mojácar, Almería, Adra, Motril-Almuñécar, Vélez Málaga y Marbella-Estepona. El proceso informativo, las visitas e inspecciones y el conjunto de instrucciones para la instauración de estas medidas, han sido analizados por extenso en Jiménez Estrella (2019).

75 El mismo era fruto de una visita realizada por don Íñigo Briceño, acompañado del ingeniero Juan de Oviedo, cuya relación fue enviada al Consejo el 22 de marzo de 1621. AGS, Guerra Antigua, leg. 872, sf. 
de la administración militar, se repetían habitualmente en numerosos memoriales y eran reiteradas por los consejeros de guerra en sus consultas. Mostraban el problema enquistado de la enorme distancia que separaban las necesidades defensivas y los recursos humanos y económicos con los que podía contar el sistema.

Sobre este punto, conviene tomar en cuenta la voz de otras instancias distintas a las autoridades militares de la costa, como es el caso del presidente de la Chancillería, al frente de la Junta de Población. De este órgano dependía, desde la expulsión de los moriscos, la administración y reparto de la consignación del personal militar de la costa (Campos Daroca, 1988). Cuatro años antes del suceso de Adra, el magistrado había puesto el acento en la comisión de abusos y fraudes en los procedimientos de libranzas de salarios, algo que no era habitualmente señalado por los oficiales de la costa. El presidente denunciaba entonces, a partir de sus propias averiguaciones, que muchos de los informes remitidos por los generales al consejo no tomaban en cuenta las plazas reales y podían estar falseados, con objeto de exagerar las deudas contraídas con la tropa. Al respecto, consideraba que en enclaves como Motril o Almería existía una diferencia notable entre la planta teórica y las plazas reales de las compañías, a menudo ocupadas por menestrales y «personas de muy poca consideración». El presidente se hacía eco de las quejas de algunas villas y particulares, reparando «en la poca razón que los oficiales de la guerra tenían de quexarse». En una clara invectiva contra pagadores, oficiales del sueldo y militares, el presidente declaraba haber sido engañado, porque para poder tomar en cuenta la deuda declarada por los generales, debían estar en pie todos los miembros de las compañías. A su parecer, la Renta de Población estaba bien administrada por la Junta y era prioritaria la conservación de la población y la cobranza de la real hacienda, «que si se dividen y no corren por una mano, todo se perderá, porque si no ay pobladores no habrá hazienda» ${ }^{76}$.

Las palabras del presidente de la Chancillería, además de darnos una visión muy diferente del problema denunciado por gobernadores y generales, muestran un pulso de largo recorrido entre ambas instancias. Mayor, si cabe, cuando desde Madrid se introdujeron cambios en la administración de la consignación, quitándola a la Junta y otorgándola a los capitanes generales (Garzón Pareja, 1982). Esta decisión, como ponía de manifiesto Íñigo Briceño en marzo de 1621, había contrariado al presidente de la Chancillería, dedicado por entonces a propagar informaciones «falsas» en las que echaba por tierra las cifras proporcionadas por el gobernador militar. En su opinión, el presidente «con esta voz altera los ánimos, de manera que los que no ven ni conocen la verdad, como desesperados claman», y que «la pasión del dicho presidente con la costa y quien la gobierna, por la mudanza que Vuestra Majestad mandó hacer de la cobranza de la consignación, es notoria y conocida». Briceño sostenía que el objetivo de la ad- 
ministración en torno a esos 400.000 ducados de deuda debía ser «poner los ojos para sacarlos de las personas en cuyo poder paran ${ }^{77}$. Para el consejo de Guerra, este último aspecto era clave y hacía necesario comisionar al contador Pérez de la Parra para que averiguase qué receptores tenían en su poder el dinero adeudado a la tropa ${ }^{78}$.

Tabla 2. Dinero recibido y librado por los pagadores de la gente de guerra, con cargo a la consignación anual de $\mathbf{3 0 . 0 0 0 . 0 0 0 ~ m a r a v e d i ́ s ~}$

\begin{tabular}{|c|c|c|}
\hline Año & Recibido & Pagado \\
\hline 1603 & $27.787 .844,0$ & $23.428 .501,5$ \\
\hline 1604 & $23.546 .360,0$ & $20.995 .485,0$ \\
\hline 1605 & $19.282 .844,0$ & $20.314 .165,0$ \\
\hline 1606 & $15.104 .788,0$ & $13.873 .581,5$ \\
\hline 1607 & $26.514 .922,0$ & $25.164 .099,5$ \\
\hline 1608 & $39.09 .6173,0$ & $34.619 .557,0$ \\
\hline 1609 & $20.055 .886,5$ & $24.802 .412,0$ \\
\hline 1610 & $17.225 .249,0$ & $19.156 .039,5$ \\
\hline 1611 & $24.308 .027,5$ & $22.686 .151,0$ \\
\hline 1612 & $25.585 .175,0$ & $19.262 .145,5$ \\
\hline 1613 & $27.124 .187,5$ & $23.062 .770,5$ \\
\hline 1614 & $13.073 .587,0$ & $23.656 .292,0$ \\
\hline 1615 & $30.000 .000,0$ & $21.845 .211,0$ \\
\hline 1616 & $13.801 .264,0$ & $24.028 .696,0$ \\
\hline 1617 & $24.659 .818,0$ & $24.657 .824,5$ \\
\hline 1618 & $16.635 .423,5$ & $15.483 .090,0$ \\
\hline 1619 & $171.88 .477,0$ & $17.991 .660,5$ \\
\hline 1620 & $24.501 .533,0$ & $24.848 .961,5$ \\
\hline 1621 & $21.374 .983,0$ & $20.075 .325,5$ \\
\hline 1622 & $23.726 .601,0$ & $24.886 .861,5$ \\
\hline 1623 & $23.444 .217,0$ & $24.446 .145,5$ \\
\hline 1624 & $24.879 .995,0$ & $24.789 .470,0$ \\
\hline Total & $498.917 .355,0$ & $494.074 .446,0$ \\
\hline
\end{tabular}

Fuente: Elaboración propia a partir de las dos resoluciones del sumario general de las cuentas de cargo y data de los pagadores Alonso Delgado de Mata (período 1602-1612) y Cristóbal Delgado de Mata (período 1612-1624), contenidas en AGS, Contaduría del Sueldo, $2^{\text {a }}$ Serie, leg. 234, sf.

El enfrentamiento dialéctico mantenido entre presidente y gobernador militar muestra dos versiones opuestas de un problema, el de los sueldos, cuya complejidad

77 AGS, Guerra Antigua, leg. 872, sf.

78 Consulta de 17/03/1621, AGS, Guerra Antigua, leg. 865, sf. Siguiendo las directrices del Consejo, se despachó la orden para comisionar al contador Joseph Pérez de la Parra para realizar las averiguaciones pertinentes sobre la deuda de 400.000 ducados, así como para cobrar el dinero a los deudores y actuar con penas de confiscación de bienes contra aquellos receptores que resultasen culpados. AGS, Guerra Antigua, lib. 130, f. 18r-19r. 
y múltiples aristas no pueden entenderse si solo nos ceñimos a las denuncias y quejas remitidas a la corte en cartas, informes y memoriales. Por ello, resulta fundamental cotejar estos testimonios con datos contables de la pagaduría, que nos permiten contar con información más fidedigna.

La tabla 2 refleja las partidas anuales de dinero que entraron en poder de los pagadores Alonso Delgado de Mata — de 1602 a 1612 - y su hijo Cristóbal — de 1612 a 1624 - con cargo a la consignación de los 80.000 ducados - 30.000 .000 maravedís - . También lo que distribuyeron por libranzas entre todo el personal militar de la costa mercedes y entretenimientos, correos, provisiones extraordinarias de trigo y cebada, proveedores y tenedores de bastimentos. Sin entrar en un examen pormenorizado de las partidas de gasto de cada año, cuyo análisis en profundidad daría para un estudio aparte, nos centraremos en los ingresos. Ello nos permite comprobar que las quejas de los generales y gobernadores de la costa estaban fundadas y las cifras que manejaban en sus memoriales y cartas no eran descabelladas. Si observamos las partidas anuales de lo que los Delgado de Mata ingresaron de la consignación, salvo en 1608 y 1615, en el resto de años, ambos pagadores nunca llegaron a recibir los 80.000 ducados en su totalidad. Muy al contrario, el déficit fue considerable en la mayoría de los años, y en 1606, 1614 y 1616, entre lo consignado y lo recibido por el pagador encontramos diferencias superiores a los 38.500 ducados -14.500 .000$ maravedís - Asimismo, en los 22 años contemplados en la tabla, podemos ver que el promedio del desfase entre lo que se suponía debía recibir el pagador a partir de la consignación y lo que realmente ingresó, se sitúa en los 19.525 ducados anuales -7.321.938 maravedís - , es decir, un 24,4\% de déficit medio anual. Esto significa que en el período que va de 1602 a 1624, la deuda acumulada, sin contar la que se arrastraba desde tiempo atrás, se situaba en unos 430.000 ducados. Esta cifra dependía de múltiples factores: la dificultad para cobrar los atrasos acumulados en las rentas que debían pagar los repobladores del reino, la mala gestión y administración de la renta o, como denunciaría en 1623 Juan Sánchez Porras al rey, la retención del dinero y su especulación por parte de receptores y demás intermediarios que participaban en el cobro de la Renta de Población (Garzón Pareja, 1982). De ello derivaban importantes demoras en la libranza de unos sueldos cuya consignación, tres años después de la muerte de Felipe III, superaría los 600.000 ducados de deuda, para no dejar de incrementarse a lo largo del XVII.

\section{Conclusiones: la defensa del reino en su contexto}

Los Habsburgo precisaron de una maquinaria burocrático-militar capaz de adaptarse a ámbitos geográficos tan distintos como la Península, Italia, Flandes, las Indias o Berbería, donde se desplegaron modelos defensivos muy distintos y adap- 
tados a las especificidades de cada territorio. Uno de esos espacios era el litoral mediterráneo, donde dispositivos castrenses como los del reino de Granada, Murcia, Valencia o Cataluña formaban parte una complicada trama defensiva en la que participaron y circularon distintos oficiales, soldados y miembros de la administración militar hispana, como hace años demostrase Thompson (Thompson, 1981). Estos coadyuvaron también a la circulación de ideas y recursos de todo tipo que, a su vez, propiciaron el establecimiento de sistemas de defensa donde se podían articular modelos y soluciones ya usadas y que funcionaban en otros territorios. En ese espacio de circulación se integraba el modelo granadino, un sistema que estaba articulado, no solo para la protección del limes marítimo peninsular, también para controlar aspectos tan importantes como el contrabando, el reparto de presas o el ejercicio de la jurisdicción militar.

Su situación no puede entenderse si no se sitúa adecuadamente en el contexto más amplio de la política defensiva y la logística aplicada por la onarquía hispánica en el Mediterráneo y los importantes cambios que se produjeron desde fines del siglo XVI. Uno de ellos fue la prioridad que se otorgó al litoral atlántico andaluz, bajo el gobierno y jurisdicción del duque de Medinasidonia, capitán general de las costas de Andalucía y de la Mar Océano (Salas Almela, 2002). El desarrollo de nuevas empresas militares en Larache y La Mamora, así como el refuerzo de las vías de aprovisionamiento y canalización de recursos hacia la Armada del Mar Océano, en relación directa con la carrera de Indias, propiciaron una progresiva marginación del litoral granadino respecto de la fachada atlántica. Por ejemplo, solo cinco días antes del ataque turco a Adra, en previsión de la llegada de cuarenta navíos ingleses y holandeses, se debían dar órdenes para que no se les dejase atracar en los puertos de la Península ni se les prestase asistencia. Ante el temor de que ambas escuadras estuviesen coordinadas para atacar a los galeones de la carrera de Indias, el consejo de Guerra consideraba fundamental proteger la plata americana. Por ello se ordenaba al marqués de Santa Cruz abandonar la misión de socorrer Ibiza y Mallorca ante los ataques de navíos turcos, y dirigirse al cabo de San Vicente para reforzar la escuadra de Portugal y la Armada del Mar Océano en la custodia de los galeones indianos ${ }^{79}$.

En este contexto y en el marco de la reformulación de la antigua posición estratégica y logística que la costa del reino de Granada había tenido durante el largo período morisco, es donde deben situarse buena parte de los problemas y defectos estructurales que se han analizado en este trabajo: crecimiento exponencial en los atrasos de la consignación para el pago de sueldos, notables diferencias entre la plan-

79 Consulta del consejo de Guerra, de 9 de octubre de 1620. AGS, Guerra Antigua, leg. 853, sf. Si bien la propuesta del consejo no se materializó, demuestra que el marco atlántico y el tráfico americano eran priorizados y antepuestos al mediterráneo. 
ta teórica y la cifra real de efectivos miliares, falta de adiestramiento, armamento y descoordinación de las milicias locales y de éstas con la tropa profesional, amén de un imparable proceso de deterioro material del cinturón de fortalezas y torres vigía. Problemas que tenían mucho que ver con las deficiencias de un modelo de provisión, administración y gestión de recursos pero que, en absoluto, eran exclusivos del cinturón militar granadino. Se trataba de un mal extendido a un sistema de protección peninsular que, en nuestra opinión, carecía de coherencia y unidad y, por ende, de una verdadera política defensiva común. Muy al contrario, existía una desarticulación que tenía mucho que ver con la adaptación a las particularidades políticas, jurídicas y geográficas de las provincias y reinos que conformaban los territorios de la monarquía. Y, no menos importante, a coyunturas y circunstancias muy determinadas y orilladas por la importante maquinaria militar desplegada en los frentes bélicos exteriores de la monarquía. Baste citar que, en octubre de 1598, recién iniciado el reinado de Felipe III, el consejo de Guerra recordaba al monarca la enorme precariedad en que se encontraban las guardias viejas de Castilla, debido a que se había priorizado el desvío de recursos a Flandes, las armadas y ejércitos del exterior, quedando la consignación de las guardas y las fronteras en el aire. Como destacaba el consejo, dado que «por acudir siempre a lo de fuera, se a tenido esto por açessorio», la deuda había aumentado de tal manera que se acumulaban importantes atrasos en las fuerzas y presidios de Fuenterrabía y San Sebastián, Aragón, Navarra, Cataluña, Peñón de Vélez, Melilla, Orán, Ibiza, Menorca, Galicia, Cádiz y Santander ${ }^{80}$. Doce años después, el consejo volvía a llamar la atención sobre la extrema necesidad en que se encontraban los soldados de los presidios y fronteras peninsulares, advirtiendo de que Su Majestad se quedaría sin hombres en ellos si no se proveía la paga por vía de la Junta de Hacienda ${ }^{81}$.

Empero, a pesar de sus muchas carencias, defectos y problemas de financiación, el granadino era uno de los aparatos castrenses mejor ordenados, estructurados y financiados, y de los más antiguos con esas características en territorio peninsular. No en vano, su sistema defensivo sirvió de modelo para otros, como el de Andalucía o el del reino de Valencia. En ellos, desde fines del siglo XVI se importaron muchos elementos del sistema de asistencia con compañías de jinetes e infantería y la red de torres vigía que desde fines del siglo Xv se venían practicando en las costas del reino granadino. En el primer caso, tuvo mucho que ver la figura del duque de Medinasidonia, capitán general de Andalucía, quien llevó a cabo la implantación de nuevas instrucciones para la defensa de la costa andaluza. En el segundo, la llegada del marqués de Mondéjar, antiguo capitán general del reino de Granada, como nuevo

80 Memorial del consejo de Guerra al rey, de 27 de octubre de 1598. AGS, Guerra Antigua, leg. 527, f. 80 .

81 Consulta del consejo, con fecha 2 de octubre de 1610. AGS, Guerra Antigua, leg. 729, sf. 
virrey de Valencia. Ambos ejemplos evidencian que, en un sistema de circulación de ideas, experiencias y modelos de gestión militar y territorial, el dispositivo castrense granadino formaba parte de una más amplia estructura defensiva que bordeaba todo el litoral peninsular. Sin embargo, sus marcadas especificidades regionales, la disparidad en sus modelos de provisión de recursos, financiación y eficacia, sus tradiciones defensivas y marcos legales muy diferentes, dificultaron que la monarquía pudiese articular una política defensiva general y unitaria en su litoral y fronteras. El del reino de Granada es un claro ejemplo de ello.

\section{AGRADECIMIENTOS}

Trabajo Financiado en el marco del Proyecto de Investigación con referencia PID2019-109489GB-I00/AEI/10.13039/501100011033, Ministerio de Ciencia e Innovación. La edición de este trabajo ha sido posible gracias a la ayuda del Programa de Grupos de Potencial Crecemento concedida por la Consellería de Cultura, Educación e Universidade da Xunta de Galicia al GI-1921 de la USC (Referencia: GPC, ED 431B 2021/06). 


\section{Bibliografía}

Alonso Acero, Beatriz (1997), Orán y Mazalquivir en la política norteafricana de España, 1589-1639, Madrid, Universidad Complutense de Madrid, [Tesis Doctoral inédita], <https://eprints.ucm.es/id/eprint/2458/1/T21541.pdf>.

Alonso AcEro, Beatriz (1999), «Entre el Mediterráneo y el Atlántico: corso europeo y corso turco berberisco en el siglo de los Felipes», en IV Centenario del ataque de Van der Does a Las Palmas de Gran Canaria (1999): Coloquio Internacional «Canarias y el Atlántico, 1580-1648», Las Palmas de Gran Canaria, Cabildo Insular de Gran Canaria, pp. 172-173.

AndúJar CAstillo, Francisco (1992-1993), «Del esclavo morisco al berberisco: sobre la esclavitud en la Almería del siglo XVII», Boletín del Instituto de Estudios Almerienses. Letras, 11-12, pp. 81-101.

Barrio Gozalo, Maximiliano (2006), «El corso y cautiverio en tiempos de Cervantes», Investigaciones Históricas, 26, pp. 81-84.

Birriel Salcedo, Margarita (1995), «Las instituciones de la repoblación del Reino de Granada (1570-1592)», en Barrios Aguilera, Manuel y Andújar Castillo, Francisco (eds.), Hombre y territorio en el Reino de Granada (1570-1630). Estudios sobre repoblación, Almería, Instituto de Estudios Almerienses, pp. 89-132.

Bunes IbarRA, Miguel Ángel (2006), «Felipe III y la defensa del Mediterráneo. La conquista de Argel», en García Hernán, Enrique y Maffi, Davide (eds.), Guerra y Sociedad en la Monarquía Hispánica. Política, Estrategia y Cultura en la Europa Moderna (1500-1700), Madrid, Laberinto, Fundación Mapfre y CSIC, Madrid, vol. I, pp. 921-946.

Bunes IbARRA, Miguel Ángel (2015), «Espionaje y creación de armadas en la época de Felipe III», en Sola, José E. y Varriale, Gennaro (coords.), Detrás de las apariencias. Información y espionaje (siglos XVI-XVII), Alcalá, Universidad de Alcalá, pp. 59-72.

BunEs IBARRA, Miguel Ángel (2016), «La jornada secreta de Argel: recursos de la monarquía de Felipe III para la organización de una operación anfibia», en Martínez Ruiz, Enrique et al. (coords.), La organización de los ejércitos, Madrid, Ministerio de Defensa, pp. 594-626.

Campos Daroca, María Luisa (1988), «Las rentas particulares del reino de Granada tras la expulsión de los moriscos en 1570. La Farda y la Renta de Población», Chronica Nova, 16, pp. 55-66. 
CAstillo FernándeZ, Javier, (1992), «Administración y recaudación de los impuestos para la defensa del reino de Granada: la farda de la mar y el servicio ordinario (1501-1516)», Áreas, 14, pp. 67-90.

Contreras Gay, José (1997), «Las milicias de socorro del Reino de Granada y su contribución a la defensa de la costa después de 1568», en actas del congreso La frontera oriental nazarí como sujeto histórico (s. XIII-XVI), Almería, Instituto de Estudios Almerienses, pp. 613-621.

Contreras Gay, José (2000), «La defensa de la frontera marítima», en Andújar Castillo, Francisco (ed.), Historia del Reino de Granada, III. Del siglo de la Crisis al fin del Antiguo Régimen (1630-1833), Granada, Universidad de Granada, pp. 145-177.

Escribano PÁez, José M. (2015), El coste de la defensa. Administración y financiación militar en Navarra durante la primera mitad del siglo XVI, Pamplona, Gobierno de Navarra.

Fontenay, Michel (1984), «Los fenómenos corsarios en la «periferización» del Mediterráneo en el siglo XVII», Áreas, 14-16, pp. 117-121.

Gámir Sandoval, Alfonso (1943), Organización de la defensa de la costa del Reino de Granada, Granada, Editorial Román Camacho.

García García, Bernardo J. (2012), «Fermosa gracia es la que el rey faze por merecimiento de servicio. Proceso y justificación de las mercedes otorgadas al valido (1618-1624)», en Esteban Estríngana, Alicia (ed.), Servir al rey en la Monarquía de los Austrias. Medios, fines y logros del servicio al soberano en los siglos XVI y XVII, Madrid, Sílex, pp. 321-359.

Garzón Pareja, Manuel (1982), «La Renta de Población del Reino de Granada», Cuadernos de la Alhambra, 18, pp. 207-229.

GonzÁlez Arévalo, Raúl (2014), «Cautiverio y esclavitud en el reino de Granada (siglos XIII-XVI)», Vínculos de Historia, 3, pp. 232-257.

Henríquez de Jorquera, Francisco (1987), Anales de Granada: descripción del reino y la ciudad de Granada, crónica de la Reconquista (1482-1492), sucesos de los años 1588 a 1646, (edición a cargo de A. Marín Ocete), Granada, Universidad de Granada.

JimÉNEZ Estrella, Antonio (2000), «La alcaidía de la Alhambra tras la rebelión morisca y su restitución al quinto marqués de Mondéjar», Chronica Nova, 27, pp. 23-51.

Jiménez Estrella, Antonio (2004), Poder, ejército y gobierno en el siglo XVI. La Capitanía General del reino de Granada y sus agentes, Granada, Universidad de Granada. 
JimÉnez Estrella, Antonio (2006), «Ejército permanente y política defensiva en el reino de Granada durante el siglo XVI», en García Hernán, Enrique y Maffi, Davide (eds.), Guerra y Sociedad en la Monarquía Hispánica. Política, Estrategia y Cultura en la Europa Moderna (1500-1700), Madrid, Laberinto -Fundación Mapfre-CSIC, vol. 1, pp. 579-610.

JimÉnez Estrella, Antonio (2007), «Linajes y alcaides en el Reino de Granada bajo los Austrias. ¿Servicio militar o fuentes de enriquecimiento y honores?», en Jiménez Estrella, Antonio y Andújar Castillo, Francisco (eds.), Los nervios de la guerra. Estudios sociales sobre el Ejército de la Monarquía Hispánica (siglos XVI-XVIII): nuevas perspectivas, Granada, Comares, pp. 89-120.

Jiménez Estrella, Antonio (2009), «Nobleza y servicio político a la Monarquía en el siglo XVI: los Mendoza y su vinculación al Reino de Granada», Obradoiro de Historia Moderna, 18, pp. 211-232.

Jiménez Estrella, Antonio (2017), «Procedimientos para el control del fraude y la corrupción en el sistema defensivo del Reino de Granada: las visitas en el siglo XVI (1516-1598)», Tiempos Modernos, vol. 8 n 35, pp. 411-431.

JimÉnez Estrella, Antonio (2019), «La amenaza del Turco en la monarquía y las instrucciones de 1621: mecanismos de control y reformas de la defensa de la costa del Reino de Granada», Memoria y Civilización, 22, pp. 343-368. < https://doi. org/10.15581/001.22.021>.

López de Coca, José E. (1989), «Tenencias de fortalezas en el Reino de Granada en la época de los Reyes Católicos (1492-1516)», en El Reino de Granada en la época de los Reyes Católicos. Repoblación, comercio, frontera, tomo II, Granada, Universidad de Granada, tomo 2, pp. 235-269.

López DE CoCA, José E. (1993), «El reino de Granada como frontera. Organización de su defensa durante el reinado de los Reyes Católicos (1492-1516)», en Cruces Blanco, Esther (coord.), La organización militar en los siglos XV y XVI, Málaga, Cátedra General Castaños, pp. 93-110.

Pardo Molero, Juan Francisco (2001), La defensa del imperio: Carlos V, Valencia y el Mediterráneo, Madrid, Sociedad Estatal para la Conmemoración de los Centenarios de Felipe II y Carlos V.

Ruiz Povedano, José M. (1979), «Problemas en torno a la reestructuración del aparato militar defensivo en el Occidente granadino a fines del siglo XV», Baética, 2, pp. 225-249

Salas Almela, Luis (2002), Colaboración y conflicto. La Capitanía General del Mar Océano y Costas de Andalucía, 1588-1660, Córdoba, Universidad de Córdoba. 
SÁnchez Ramos, Valeriano (1995), «Repoblación y defensa en el reino de Granada: campesinos-soldados y soldados-campesinos», Chronica Nova, 22, pp. 357-388.

SÁnchez Ramos, Valeriano (2010), «Terror al turco. La traumática toma de Adra de 1620», Andalucía en la Historia, 29, pp. 10-13.

Soria Mesa, Enrique (1995), La venta de señoríos en el Reino de Granada bajo los Austrias, Granada, Universidad de Granada.

Szmolka Clares, José (1979), «La organización militar en el antiguo Reino de Granada», Anuario de Historia Contemporánea, 6, pp. 83-106.

Thompson, Irving A. A. (1981), Guerra y decadencia. Gobierno y Administración en la España de los Austrias, 1560-1620, Barcelona, Crítica.

Truchuelo García, Susana (2004), Guipúzcoa y el poder real en la Alta Edad Moderna, San Sebastián, Diputación Foral de Guipúzcoa.

Truchuelo García, Susana (2012), «Militares en el mundo urbano fronterizo castellano (siglos XVI-XVII)», Studia Historica. Historia Moderna, 34, pp. 145-180.

Velasco Hernández, Francisco (2012), «Corsarios y piratas ingleses y holandeses en el Sureste español durante el reinado de Felipe III (1598-1621)», Investigaciones históricas, 32, pp. 89-118.

Vera Delgado, Ana M. (1986), La última frontera medieval: la defensa costera en el obispado de Málaga en tiempos de los Reyes Católicos, Málaga, Diputación Provincial de Málaga.

VINCENT, Bernard (1985), «Las rentas particulares del reino de Granada en el siglo XVI: fardas, habices y agüela», en Andalucía en la Edad Moderna: Economía y Sociedad, Granada, Diputación Provincial, pp. 81-122. 